\title{
IncRNA HAND2-AS1 inhibits cancer cell proliferation, migration and invasion by downregulating ROCK1 in HPV-positive and negative cervical squamous cell carcinoma
}

\author{
LIPING JIN $^{1 *}$, JINGQUAN JI ${ }^{2 *}$, LINJIE SHI ${ }^{3}$, SHUANGLING JIN ${ }^{1}$ and LIHUA PEI ${ }^{1}$ \\ ${ }^{1}$ Department of Gynaecology and Obstetrics, Heping Hospital Affiliated to Changzhi Medical College; \\ ${ }^{2}$ Department of Pathophysiology, Changzhi Medical College; ${ }^{3}$ Department of Urology, Heping Hospital \\ Affiliated to Changzhi Medical College, Changzhi, Shanxi 046000, P.R. China
}

Received August 8, 2018; Accepted March 26, 2019

DOI: $10.3892 /$ etm.2019.7830

\begin{abstract}
Long non-coding (lnc)RNA HAND2 antisense RNA 1 (HAND2-AS1) exhibited tumor suppression activity in different types of cancer. However, its role in cervical squamous cell carcinoma (CSCC), which is frequently diagnosed among females, has not been elucidated. The current study revealed that IncRNA HAND2-AS1 was downregulated, while Rho-associated protein kinase 1 (ROCK1) was upregulated in serum of human papillomavirus (HPV)-positive and -negative patients with CSCC compared with healthy controls. Correlation analysis revealed that the expression levels of lncRNA HAND2-AS1 were negatively correlated with the expression levels of ROCK1 in HPV-positive and -negative patients with CSCC but not in healthy controls. Downregulation of 1ncRNA HAND2-AS1 distinguished patients with CSCC from healthy controls. Additionally, lncRNA HAND2-AS1 overexpression led to reduced expression levels of ROCK1 in HPV-positive and -negative human CSCC cell lines but not in normal cervical cell lines. ROCK1 overexpression did not significantly affect the expression of lncRNA HAND2-AS1 in all the cell lines investigated. IncRNA HAND2-AS1 overexpression inhibited, while ROCK1 overexpression promoted the proliferation, migration and invasion of HPV-positive and -negative human CSCC cell lines but not normal cervical cell lines. ROCK1 overexpression attenuated the effects of lncRNA HAND2-AS1 overexpression on cancer cell proliferation, migration and invasion. IncRNA HAND2-AS1 may
\end{abstract}

Correspondence to: Dr Liping Jin, Department of Gynaecology and Obstetrics, Heping Hospital Affiliated to Changzhi Medical College, 110 Yan'an South Road, Changzhi, Shanxi 046000, P.R. China

E-mail: rsqanw7@163.com

${ }^{*}$ Contributed equally

Key words: cervical squamous cell carcinoma, lncRNA HAND2-AS1, ROCK1, human papillomavirus, cancer cells inhibit cancer cell proliferation, migration and invasion by downregulating ROCK1 in HPV-positive and -negative CSCC.

\section{Introduction}

Cervical cancer is one of the most frequently diagnosed malignancies among females, and results in >10,000 new cases and $>4,000$ mortalities in the United States every year (1). Cervical cancer is considered the leading cause of cancer-associated deaths in certain African and Asian countries (2). In spite of the efforts made to improve the treatment of cervical cancer, the 5-year survival rate in China remains $<50 \%$ (3). Cervical squamous cell carcinoma (CSCC) is the most common type of cervical cancer and accounts for $>90 \%$ of the cases (4). Human papillomavirus (HPV) infection is the major cause of CSCC (5). Incidence of HPV-positive CSCC has been significantly reduced with the HPV infection screening program (6). However, HPV-negative CSCC is more aggressive than HPV-positive CSCC and has an increasing incidence rate (7).

Previous studies revealed that long non-coding (lnc)RNAs serve important roles in cancer biology $(8,9)$. IncRNAs have potential diagnostic and therapeutic efficacy in certain types of malignant tumors, including lung and liver cancer (10). lncRNA HAND2 antisense RNA 1 (HAND2-AS1) exhibited tumor suppressor effects in several types of cancer including osteosarcoma (11) and endometrioid endometrial carcinoma (12). A previous study revealed that the HAND2-AS1 expression level in HPV-positive patients with CSCC was negatively correlated with that of Rho-associated protein kinase 1 (ROCK1), which serves an oncogenic role in cancer biology (13). The present study demonstrated that lncRNA HAND2-AS1 may inhibit cancer cell proliferation, migration and invasion by downregulating ROCK1 in HPV-positive and -negative CSCC.

\section{Materials and methods}

Patients and serum specimens. A total of 122 patients with CSCC were admitted to Heping Hospital Affiliated to Changzhi Medical College (Changzhi, China) between May 2015 and January 2018. The present study included 22 HPV-16 
positive cases, 18 HPV-18-positive cases and 20 HPV-negative cases. Patients were diagnosed based on HPV infection detection results obtained using sensitive polymerase chain reaction (PCR) techniques (14). The inclusion criteria were as follow: i) CSCC diagnosis by pathological examinations; ii) normal function in other organs; iii) stage I and II CSCC; and iv) patients willing to participate in the current study and who signed informed consent forms. The exclusion criteria were as follows: i) Severe co-morbidities; ii) treatment prior to admission; iii) multiple HPV strain infections; and iv) patients who could not fully understand the experimental protocol. The age of the 22 HPV-16-positive patients ranged between 23 and 67 years, with a mean age of $46.1 \pm 7.1$ years. The age of the 18 HPV-18 positive patients ranged between 24 and 68 years, with a mean age of $46.3 \pm 6.6$ years. The age of the $20 \mathrm{HPV}$ negative patients ranged between 24 and 65 years, with a mean age of $45.9 \pm 5.8$ years. The present study included 24 healthy volunteers who received examinations during the same time to serve as the control group. The age of healthy volunteers ranged between 22 and 68 years, with a mean age of $45.4 \pm 6.9$ years. There were no significant differences in age among the groups. The Ethics Committee of Peace Hospital of Changzhi Medical College approved the current study. Blood was extracted from the elbow vein of each participant prior to breakfast the day following admission to prepare serum through centrifugation at $1,400 \mathrm{x}$ g for $20 \mathrm{~min}$ at room temperature. Serum was stored in liquid nitrogen until required.

Reverse transcription (RT)-qPCR. Total RNA was extracted from serum and cells using TRIzol ${ }^{\circledR}$ reagent (Invitrogen; Thermo Fisher Scientific, Inc.) according to the manufacturer's protocol. Total RNA was reverse transcribed into cDNA using the SuperScript III Reverse Transcriptase kit (Thermo Fisher Scientific, Inc.) according to the manufacturer's protocol. qPCR was subsequently performed using the SYBR ${ }^{\circledR}$ Green PCR Master mix (Thermo Fisher Scientific, Inc.) according to manufacturer's instructions. The following primers pairs were used for the qPCR: 1ncRNA HAND2-AS1 forward, 5'-GGG TGTTTACGTAGACCAGAACC-3' and reverse, 5'-CTTCCA AAAGCCTTCTGCCTTAG-3'; and $\beta$-actin forward, 5'-GAC CTCTATGCCAACACAGT-3' and reverse, 5'-AGTACTTGC GCTCAGGAGGA-3'. The following thermocycling conditions were used: Initial denaturation at $95^{\circ} \mathrm{C}$ for $1 \mathrm{~min}$, followed by 40 cycles of $95^{\circ} \mathrm{C}$ for $15 \mathrm{sec}$ and $56^{\circ} \mathrm{C}$ for $35 \mathrm{sec}$. mRNA levels were quantified using the $2^{-\Delta \Delta \mathrm{Cq}}$ method and normalized to the internal reference gene $\beta$-actin (15).

ELISA. Serum levels of ROCK1 were measured using an ELISA kit purchased from Abcam (cat. no. ab211175) according to manufacturer's instructions. The sensitivity of this kit was $0.1 \mathrm{pg} / \mathrm{ml}$ and the assay range was $2.5-80 \mathrm{ng} / \mathrm{ml}$.

Cell culture and transfection. C-33 A (HPV negative) and SiHa (HPV positive) human CSCC cell lines, and HCvEpC (HPV negative) and Ect1/E6E7 (HPV positive) human cervical epithelial cell lines were purchased from the American Type Culture Collection (ATCC). The cells were cultured in Eagle's Minimum Essential Medium (EMEM; ATCC) containing 10\% FBS (ATCC). Cell culture conditions were $37^{\circ} \mathrm{C}$ and $5 \% \mathrm{CO}_{2}$. IncRNA HAND2-AS1 and ROCK1
pIRSE2 expression vectors as well as empty pIRSE2 vectors were purchased from GeneCopoeia, Inc. Lipofectamine ${ }^{\circledR}$ 2000 reagent (cat no. 11668-019; Invitrogen; Thermo Fisher Scientific, Inc.) was used to transfect $10 \mathrm{nM}$ of the vectors into the cancer cell lines $(10 \mathrm{nM}$ for each vector in case of double transfections). Cancer cells transfected with empty vectors served as the negative control (NC) group. Cells without transfection were used as control (C) cells. An overexpression rate $>180 \%$ (range, $180-225 \%$ ) was demonstrated by RT-qPCR at $24 \mathrm{~h}$ post-transections prior to subsequent experiments.

Cell proliferation assay. The Cell Counting Kit-8 (CCK-8) assay (Sigma-Aldrich; Merck KGaA) was performed to measure cell proliferation following transfection. Briefly, cells were harvested and resuspended to a cell density of $4 \times 10^{4}$ cells $/ \mathrm{ml}$. Each well of a $96-$ well plate was filled with $0.1 \mathrm{ml}$ cell suspension and incubated at $37^{\circ} \mathrm{C}$ in a $5 \% \mathrm{CO}_{2}$ incubator. A total of $10 \mu \mathrm{l}$ CCK-8 cell solution was added into each well following 24, 48, 72 and $96 \mathrm{~h}$ of incubation. Cells were cultured for an additional $4 \mathrm{~h}$, followed by measurement of optical density values at a wavelength of $450 \mathrm{~nm}$ using a microplate reader.

Transwell migration and invasion assay. Transwell migration and invasion assays were performed to investigate cell migration and invasion following transfection. Briefly, cells were harvested and cell suspensions $\left(4 \times 10^{4}\right.$ cells $\left./ \mathrm{ml}\right)$ were prepared using serum-free EMEM. A total of $4 \times 10^{3}$ cells in $0.1 \mathrm{ml}$ cell suspension were seeded in the upper chamber of the insert, while the lower chamber was filled with RPMI-1640 medium (Thermo Fisher Scientific, Inc.) containing 20\% fetal calf serum (Sigma-Aldrich; Merck KGaA). The upper chamber was coated with Matrigel ${ }^{\circledR}$ (cat no. 356234; EMD Millipore) prior to the invasion assay at $37^{\circ} \mathrm{C}$ for $6 \mathrm{~h}$. Cells were cultured at $37^{\circ} \mathrm{C}$ in a $5 \% \mathrm{CO}_{2}$ incubator for $12 \mathrm{~h}$. Migrated and invaded cells were stained with $0.5 \%$ crystal violet (Sigma-Aldrich, Merck KGaA) for $20 \mathrm{~min}$ at room temperature. Cells were observed and counted under a light microscope. Five visual fields were selected for each sample to count cell number (magnification, x50).

Western blot analysis. Total protein was extracted from cells using radioimmunoprecipitation assay buffer (Thermo Fisher Scientific, Inc.) and quantified using a bicinchoninic acid assay. Following denaturation in boiling $\left(100^{\circ} \mathrm{C}\right)$ water for $5 \mathrm{~min}, 20 \mu \mathrm{g}$ protein/lane was separated via SDS-PAGE on a $10 \%$ gel. The separated proteins were subsequently transferred onto a polyvinylidene difluoride membrane. Following incubation in 5\% skimmed milk for $2 \mathrm{~h}$ at room temperature, the membranes were incubated with antibodies against ROCK1 (1:1,200; cat no. ab97592; Abcam) and GAPDH (1:1,200; cat no. ab37168; Abcam) overnight at $4^{\circ} \mathrm{C}$. The membranes were subsequently incubated with a horseradish peroxidase-labeled secondary antibodies (1:1,000; cat no. MBS435036; MyBioSource, Inc.) at room temperature for $2 \mathrm{~h}$. Signal development was performed using BM Chemiluminescence ELISA substrate (Sigma-Aldrich, Merck KGaA). Data normalization was performed using ImageJ software (version 1.6; National Institutes of Health). 


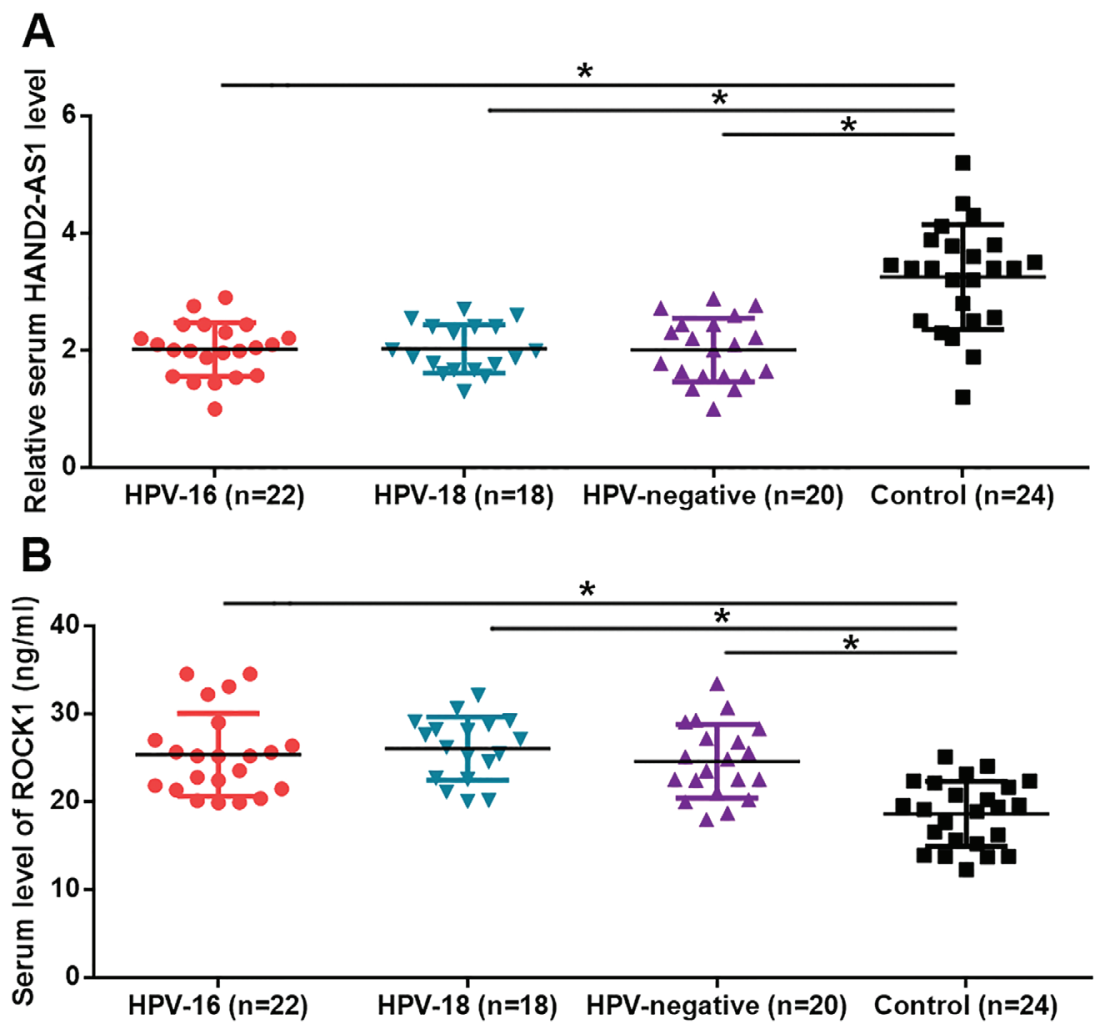

Figure 1. HAND2-AS1 is downregulated and ROCK1 is upregulated in HPV-positive and negative patients with CSCC compared with healthy controls. (A) HAND2-AS1 was downregulated and (B) ROCK1 was upregulated in HPV-positive and -negative patients with cervical squamous cell carcinoma compared with healthy controls. ${ }^{*} \mathrm{P}<0.05$. HAND2-AS1, HAND2 antisense RNA 1; ROCK1, rho associated coiled-coil containing protein kinase 1; HPV, human papillomavirus.

Statistical analysis. SPSS software (version 19; IBM Corp) was used for statistical analysis. Data were expressed as mean \pm standard deviation. Comparisons among multiple groups were performed using the one way analysis of variance followed by the Tukey test. Correlations between the serum levels of lncRNA HAND2-AS1 and ROCK1 were analyzed by the Pearson's correlation test. Receiver operating characteristic (ROC) curve analysis was performed to evaluate the diagnostic value of serum lncRNA HAND2-AS1 for CSCC. P $<0.05$ was considered to indicate a statistical significant difference.

\section{Results}

HAND2-AS1 is downregulated and ROCK1 is upregulated in $H P V$-positive and negative patients with CSCC compared with healthy controls. Serum levels of HAND2-AS1 and ROCK1 in all subjects were measured using RT-qPCR and ELISA, respectively. Compared with the control group, HAND2-AS1 was downregulated $(\mathrm{P}<0.05$; Fig. $1 \mathrm{~A})$, while ROCK1 $(\mathrm{P}<0.05$; Fig. 1B) was upregulated in all three groups of patients with CSCC. However, no significant differences in the serum levels of HAND2-AS1 and ROCK1 were found among the three groups of patients with CSCC.

Serum levels of HAND2-AS1 and ROCK1 were negatively correlated in HPV-positive and-negative CSCC patients but not in healthy controls. Pearson correlation coefficient analysis revealed a reverse correlation between serum levels of HAND2-AS1 and ROCK1 in HPV-16-positive CSCC patients (Fig. 2A), HPV-18-positive CSCC patients (Fig. 2B) and HPV-negative CSCC patients (Fig. 2C) but not in healthy controls (Fig. 2D).

Downregulation of IncRNA HAND2-AS1 distinguished CSCC patients from healthy controls. ROC curve analysis was performed to evaluate the diagnostic value of serum lncRNA HAND2-AS1 for different types of CSCC. For HPV-16-positive CSCC, the area under the curve (AUC) was 0.8930 , with standard error of 0.05144 and $95 \%$ confidence interval of 0.7922-0.9938 ( $\mathrm{P}<0.001$; Fig. 3A). For HPV-18-positive CSCC, the AUC was 0.8866 , with standard error of 0.05295 and $95 \%$ confidence interval of 0.7828-0.9904 ( $\mathrm{P}<0.001$; Fig. 3B). For HPV-negative CSCC, the AUC was 0.8781, with standard error of 0.05311 and $95 \%$ confidence interval of $0.7740-0.9822$ $(\mathrm{P}<0.001$; Fig. 3C). For all types of CSCC, the AUC was 0.8861 , with standard error of 0.04901 and $95 \%$ confidence interval of $0.79000-0.9822$ ( $\mathrm{P}<0.001$; Fig. 3D).

IncRNA HAND2-AS1 downregulated ROCK1 in both $H P V$-positive and-negative CSCC cells but not in normal cells. To further investigate the interactions between IncRNA HAND2-AS1 and ROCK1, lncRNA HAND2-AS1 and ROCK1 expression vectors were transfected into cells. The expression of IncRNA HAND2-AS1 and ROCK1 were detected by RT-qPCR and western blot, respectively. Compared with cells in the $\mathrm{C}$ and NC groups, lncRNA HAND2-AS1 overexpression led to the downregulation of ROCK1 expression in C-33 A (HPV negative) and SiHa (HPV positive) CSCC cell lines 

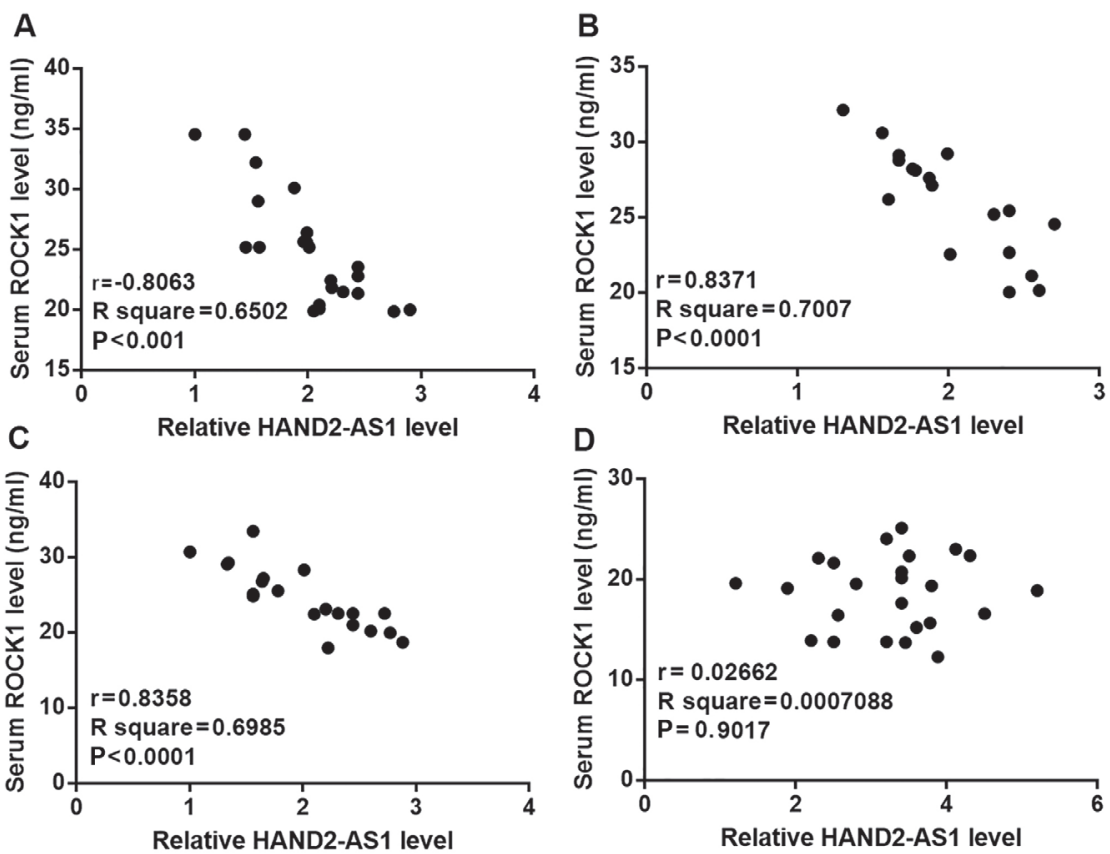

Figure 2. Serum levels of HAND2-AS1 and ROCK1 were negatively correlated in HPV-positive and negative patients with CSCC but not in healthy controls. Serum levels of HAND2-AS1 and ROCK1 were negatively correlated in (A) HPV-16-positive patients with CSCC, (B) HPV-18-positive patients with CSCC and (C) HPV-negative patients with CSCC but not in (D) healthy controls. HAND2-AS1, HAND2 antisense RNA 1; ROCK1, rho associated coiled-coil containing protein kinase 1; HPV, human papillomavirus; CSCC, cervical squamous cell carcinoma.
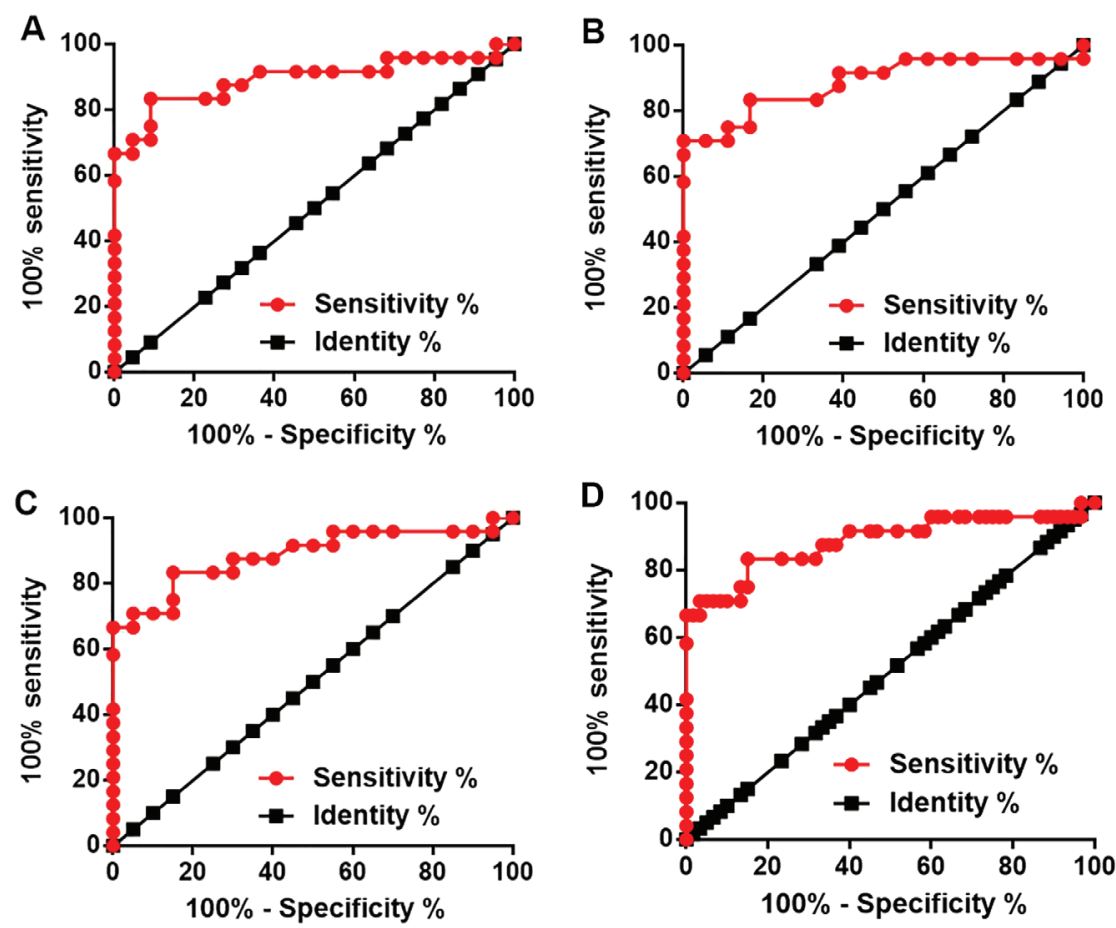

Figure 3. Downregulation of HAND2-AS1 distinguished patients with CSCC from healthy controls. Receiver operating characteristics curve analysis revealed that downregulation of HAND2-AS1 distinguished (A) HPV-16-positive patients with CSCC, (B) HPV-18-positive patients with CSCC, (C) HPV-negative patients with CSCC and (D) all types of patients with CSCC from healthy controls. HAND2-AS1, HAND2 antisense RNA 1; CSCC, cervical squamous cell carcinoma; HPV, human papillomavirus.

$(\mathrm{P}<0.05)$, but not in HCvEpC (HPV negative) and Ect1/E6E7 (HPV positive) human cervical epithelial cell lines (Fig. 4A). By contrast, ROCK1 overexpression resulted in no significant effects on the expression of lncRNA HAND2-AS1 in all four cell lines (Fig. 4B).
IncRNA HAND2-AS1 and ROCK1 serve opposing roles in the proliferation, migration and invasion of CSCC cells. Compared with cells in the C group, IncRNA HAND2-AS1 overexpression significantly inhibited, while ROCK1 overexpression significantly promoted the proliferation (Fig. 5A), migration 
A
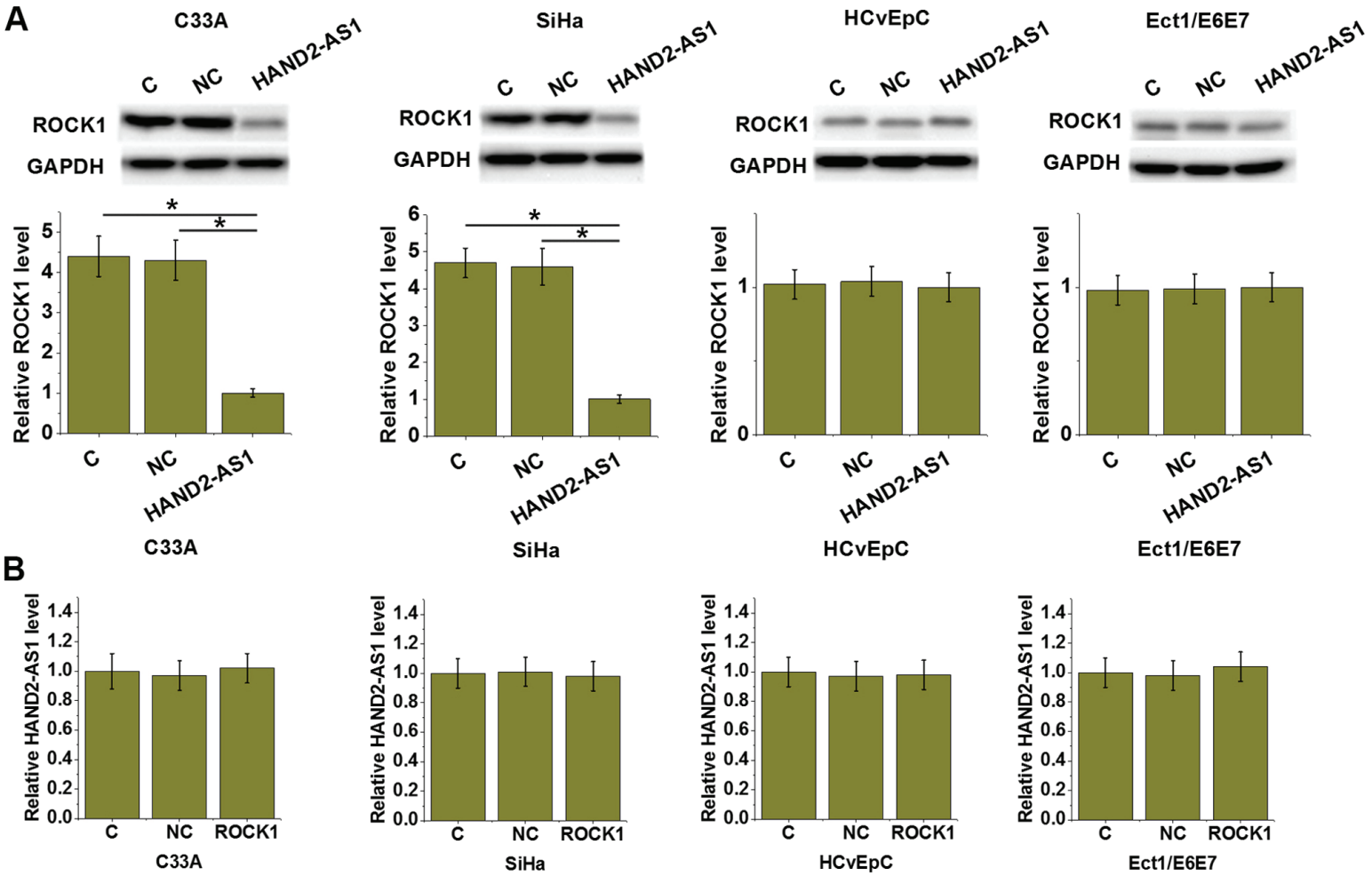

Figure 4. IncRNA HAND2-AS1 downregulated ROCK1 expression in HPV-positive and negative CSCC cells but not in normal cells. (A) lncRNA HAND2-AS1 overexpression led to downregulated ROCK1 expression in C-33A and SiHa human CSCC cell lines but not in HCvEpC (HPV negative) and Ect1/E6E7 (HPV positive) human cervical epithelial cell lines. (B) ROCK1 overexpression resulted in no significant effects on lncRNA HAND2-AS1 expression in all 4 cell lines. "P<0.05. 1ncRNA, long non-coding RNA; HAND2-AS1, HAND2 antisense RNA 1; ROCK1, rho associated coiled-coil containing protein kinase 1; HPV, human papillomavirus; CSCC, cervical squamous cell carcinoma; C, control; NC, negative control.

(Fig. 5B) and invasion (Fig. 5C) of C-33 A (HPV negative) and $\mathrm{SiHa}$ (HPV positive) human CSCC cell lines $(\mathrm{P}<0.05)$, but not of HCvEpC (HPV negative) and Ect1/E6E7 (HPV positive) human cervical epithelial cell lines (data not shown). In addition, ROCK1 overexpression significantly attenuated the inhibitory effects of lncRNA HAND2-AS1 overexpression on the proliferation (Fig. 5A), migration (Fig. 5B) and invasion (Fig. 5C) of cancer cells $(\mathrm{P}<0.05)$.

\section{Discussion}

The role of 1ncRNA HAND2-AS1 has been previously characterized in two types of human malignancies including osteosarcoma (11) and endometrioid endometrial carcinoma (12). The present study revealed that IncRNA HAND2-AS1 serves a tumor suppressor role in HPV-negative and HPV-positive CSCC cells, possibly by downregulating ROCK1.

Downregulation of lncRNA HAND2-AS1 was previously reported in osteosarcoma (11) and endometrioid endometrial carcinoma (12). Overexpression of lncRNA HAND2-AS1 inhibited the progression of the aforementioned malignancies, indicating that IncRNA HAND2-AS1 may be a potential therapeutic target for osteosarcoma (11) and endometrioid endometrial carcinoma (12). The current study revealed that serum IncRNA HAND2-AS1 was downregulated in HPV-positive and -negative patients with CSCC compared with healthy controls. In addition, IncRNA HAND2-AS1 overexpression inhibited the proliferation, migration and invasion of HPV-positive and -negative human CSCC cells in vitro. HAND2-AS1 overexpression resulted in no significant effects on the biological behaviors of normal human cervical epithelial cells. The data obtained in the present study suggested that IncRNA HAND2-AS1 may serve as a potential therapeutic target for CSCC.

Tumor metastasis leads to high mortality rate among cancer patients. Patients with metastatic CSCC usually have a poor prognosis even following treatment $(16,17)$. Therefore, early diagnosis and treatment are required to improve the overall survival rate of patients with CSCC. The present study enrolled patients with CSCC at stages I and II, which are the two early stages of CSCC. ROC curve analysis revealed that upregulated plasma lncRNA HAND2-AS1 effectively distinguished HPV-16-positive, HPV-18-positive and HPV-negative patients from healthy controls. Therefore, plasma lncRNA HAND2-AS1 may have diagnostic value for HPV-positive and -negative CSCC. However, IncRNA HAND2-AS1 expression is also altered in osteosarcoma (11) and endometrioid endometrial carcinoma (12). Therefore, multiple biomarkers may improve the diagnostic specificity for CSCC.

ROCK1 is a protein serine/threonine kinase that serves important roles in cancer development and progression, particularly in cell motility, metastasis and angiogenesis $(18,19)$. Inhibition of ROCK1 may be a promising therapeutic target for the treatment of cancer $(18,19)$. ROCK1 interacts with IncRNAs to participate in the pathogenesis of certain types of malignancies, such as osteosarcoma $(20,21)$. The current study revealed that IncRNA HAND2-AS1 may be an upstream 

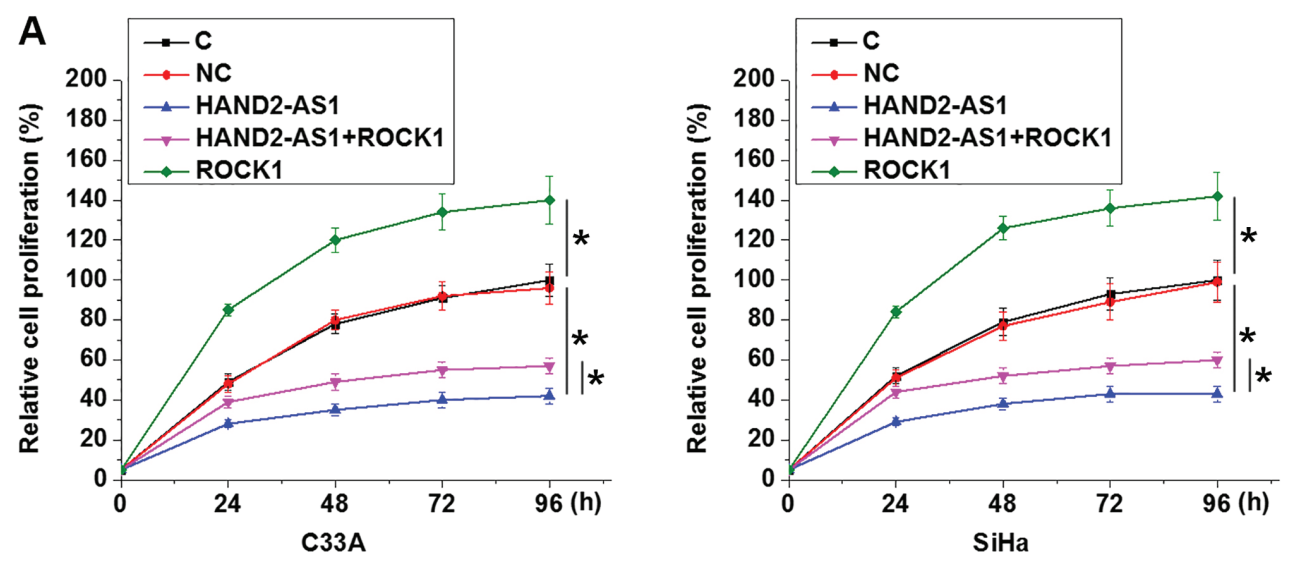

B
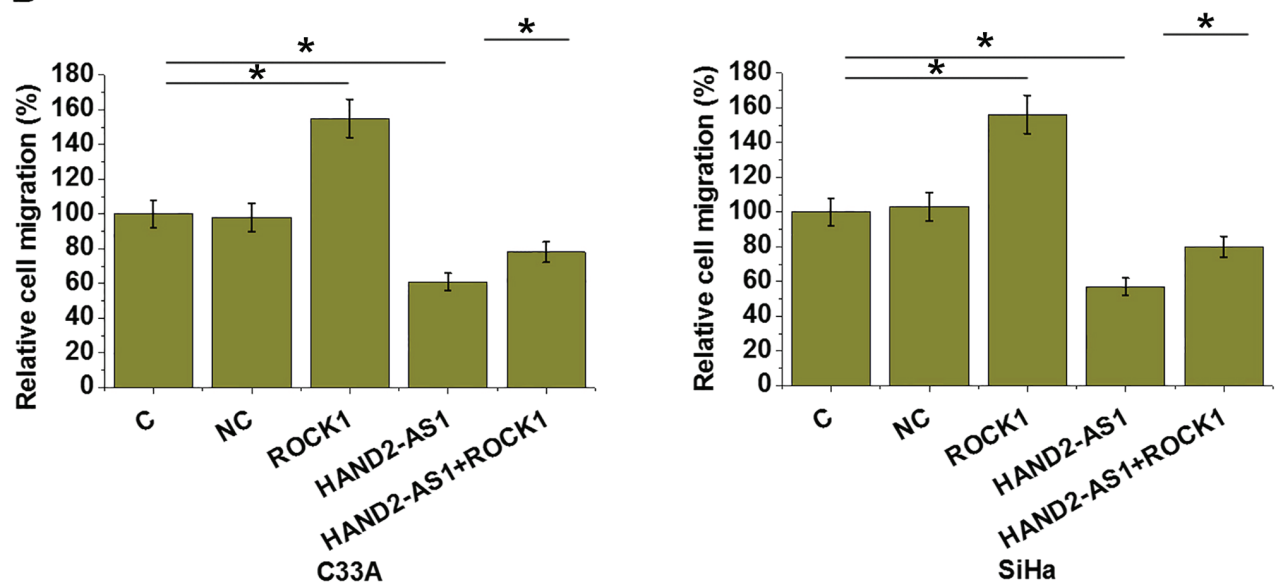

C
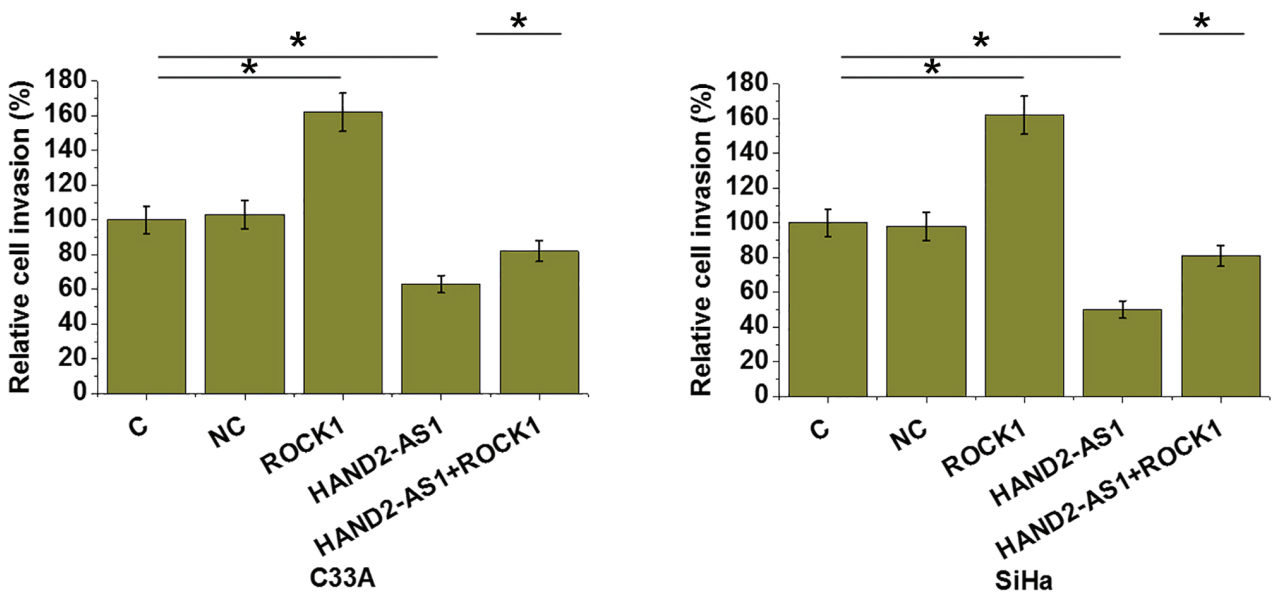

Figure 5. 1ncRNA HAND2-AS1 and ROCK1 serve opposite roles in proliferation, migration and invasion of CSCC cells. HAND2-AS1 overexpression significantly inhibited, while ROCK1 overexpression significantly promoted the (A) proliferation (B) migration and (C) invasion of C-33 A and SiHa human CSCC cell lines. In addition, ROCK1 overexpression significantly attenuated the inhibitory effects of lncRNA HAND2-AS1 overexpression on proliferation, migration and invasion of cancer cells. " $\mathrm{P}<0.05$. The relative cell migration and invasion were calculated by normalizing cell number to control group, which was set to $100 \%$. lncRNA, long non-coding RNA; HAND2-AS1, HAND2 antisense RNA 1; ROCK1, rho associated coiled-coil containing protein kinase 1; $\mathrm{HPV}$, human papillomavirus; CSCC, cervical squamous cell carcinoma; C, control; NC, negative control.

inhibitor of ROCK1 in HPV-positive and -negative CSCC. The present study suggests that disease-associated factors may mediate the interaction between lncRNA HAND2-AS1 and ROCK1: i) No significant correlation between plasma lncRNA HAND2-AS1 and ROCK1 were observed in normal controls; and ii) lncRNA HAND2-AS1 overexpression did not significantly affect ROCK1 in normal human cervical epithelial cells. ROCK1 overexpression only partially attenuated the inhibitory effects of lncRNA HAND2-AS1 on CSCC cell proliferation, migration and invasion. Therefore, lncRNA HAND2-AS1 may also interact with other pathways to achieve this regulatory role. Furthermore, the data obtained in the current study suggested that HPV-positive and -negative CSCC may share similar pathological pathways.

To the best of the authors' knowledge, the current study is the first to investigate the role of HAND2-AS1 in CSCC. 
The current study systemically investigated the role of HAND2-AS1 in different types of CSCC and evaluated the diagnostic value of HAND2-AS1 for CSCC. The current study provided new insights into the pathogenesis of CSCC. In conclusion, lncRNA HAND2-AS1 was downregulated and ROCK1 was upregulated in HPV-positive and -negative patients with CSCC. IncRNA HAND2-AS1 may inhibit cancer cell proliferation, migration and invasion by downregulating ROCK1 in HPV-positive and -negative CSCC.

\section{Acknowledgements}

Not applicable.

\section{Funding}

No funding was received.

\section{Availability of data and materials}

The datasets used and/or analyzed during the current study are available from the corresponding author on reasonable request.

\section{Authors' contributions}

LJ designed experiments. $\mathrm{LJ}$ and $\mathrm{JJ}$ performed experiments. LS, SJ and LP analyzed data. LJ drafted the manuscript. All authors have given final approval of the version to be published.

\section{Ethics approval and consent to participate}

The present study was approved by The Ethics Committee of the Peace Hospital of Changzhi Medical College (Changzhi, China). All patients and healthy volunteers provided written informed consent prior to their inclusion in the study.

\section{Patient consent for publication}

Not applicable.

\section{Competing interests}

The authors declare that they have no competing interests.

\section{References}

1. DeSantis CE, Siegel RL, Sauer AG, Miller KD, Fedewa SA, Alcaraz KI and Jemal A: Cancer statistics for African Americans, 2016: Progress and opportunities in reducing racial disparities. CA Cancer J Clin 66: 290-308, 2016.

2. Torre LA, Bray F, Siegel RL, Ferlay J, Lortet-Tieulent J and Jemal A: Global cancer statistics, 2012. CA Cancer J Clin 65: 87-108, 2015.

3. Zheng R, Zeng $\mathrm{H}$, Zhang S, Chen $\mathrm{T}$ and Chen $\mathrm{W}$ : National estimates of cancer prevalence in China, 2011. Cancer Lett 370: 33-38, 2016.
4. Waggoner SE: Cervical cancer. Lancet 361: 2217-2225, 2003.

5. Crosbie EJ, Einstein MH, Franceschi S and Kitchener HC: Human papillomavirus and cervical cancer. Lancet 382: 889-899, 2013.

6. Hildesheim A, Gonzalez P, Kreimer AR, Wacholder S, Schussler J, Rodriguez AC, Porras C, Schiffman M, Sidawy M, Schiller JT, et al: Impact of human papillomavirus (HPV) 16 and 18 vaccination on prevalent infections and rates of cervical lesions after excisional treatment. Am J Obstet Gynecol 215: 212. e1-212.e15, 2016

7. Rodríguez-Carunchio L, Soveral I, Steenbergen RD, Torné A, Martinez S, Fusté P, Pahisa J, Marimon L, Ordi J and del Pino M: HPV-negative carcinoma of the uterine cervix: A distinct type of cervical cancer with poor prognosis. BJOG 122: 119-127, 2015.

8. Spizzo R, Almeida MI, Colombatti A and Calin GA: Long non-coding RNAs and cancer: A new frontier of translational research? Oncogene 31: 4577-4587, 2012.

9. Gutschner T and Diederichs S: The hallmarks of cancer: A long non-coding RNA point of view. RNA Biol 9: 703-719, 2012.

10. Qi P and Du X: The long non-coding RNAs, a new cancer diagnostic and therapeutic gold mine. Mod Pathol 26: 155-165, 2013.

11. Kang Y, Zhu X, Xu Y, Tang Q, Huang Z, Zhao Z, Lu J, Song G, $\mathrm{Xu} \mathrm{H}$, Deng $\mathrm{C}$ and Wang J: Energy stress-induced lncRNA HAND2-AS1 represses HIF1 $\alpha$-mediated energy metabolism and inhibits osteosarcoma progression. Am J Cancer Res 8: 526-537, 2018.

12. Yang X, Wang CC, Lee WYW, Trovik J, Chung TKH and Kwong J: Long non-coding RNA HAND2-AS1 inhibits invasion and metastasis in endometrioid endometrial carcinoma through inactivating neuromedin U. Cancer Lett 413: 23-34, 2018.

13. Wei L, Surma M, Shi S, Lambert-Cheatham N and Shi J: Novel insights into the roles of Rho kinase in cancer. Arch Immunol Ther Exp (Warsz) 64: 259-278, 2016.

14. Kardani K, Agi E and Bolhassani A: Diagnosis of HPV Infections, HPV Testing in Patients. In: HPV Infections: Diagnosis, Prevention, and Treatment. Bolhassani (ed.). Bentham Science Publishers Ltd., Sharjah, pp129-158, 2018.

15. Livak KJ and Schmittgen TD: Analysis of relative gene expression data using real-time quantitative PCR and the 2(-Delta Delta C(T)) method. Methods 25: 402-408, 2001.

16. Friedlander M and Grogan M; U.S. Preventative Services Task Force: Guidelines for the treatment of recurrent and metastatic cervical cancer. Oncologist 7: 342-347, 2002.

17. Symonds RP, Gourley C, Davidson S, Carty K, McCartney E, Rai D, Banerjee S, Jackson D, Lord R, McCormack M, et al: Cediranib combined with carboplatin and paclitaxel in patients with metastatic or recurrent cervical cancer (CIRCCa): A randomised, double-blind, placebo-controlled phase 2 trial. Lancet Oncol 16: 1515-1524, 2015.

18. Whatcott CJ, Ng S, Barrett MT, Hostetter G, Von Hoff DD and Han H: Inhibition of ROCK1 kinase modulates both tumor cells and stromal fibroblasts in pancreatic cancer. PLoS One 12: e0183871, 2017.

19. Chin VT, Nagrial AM, Chou A, Biankin AV, Gill AJ, Timpson $P$ and Pajic M: Rho-associated kinase signalling and the cancer microenvironment: Novel biological implications and therapeutic opportunities. Expert Rev Mol Med 17: e17, 2015.

20. Cui M, Wang J, Li Q, Zhang J, Jia J and Zhan X: Long non-coding RNA HOXA11-AS functions as a competing endogenous RNA to regulate ROCK1 expression by sponging miR-124-3p in osteosarcoma. Biomed Pharmacother 92: 437-444, 2017.

21. Wang Y, Zeng X, Wang N, Zhao W, Zhang X, Teng S, Zhang Y and Lu Z: Long noncoding RNA DANCR, working as a competitive endogenous RNA, promotes ROCK1-mediated proliferation and metastasis via decoying of miR-335-5p and miR-1972 in osteosarcoma. Mol Cancer 17: 89, 2018.

This work is licensed under a Creative Commons Attribution-NonCommercial-NoDerivatives 4.0 International (CC BY-NC-ND 4.0) License. 